\title{
Adaptation à la sécheresse et création variétale : le cas de l'arachide en zone sahélienne
}

\author{
Première partie : revue bibliographique
}

Danièle CLAVEL ${ }^{1}$ Nani K. DRAME ${ }^{2}$

Ndèye D. DIOP ${ }^{3}$

Y. ZUILY-FODIL ${ }^{2}$

${ }^{1}$ CIRAD (Centre de coopération internationale en recherche agronomique

pour le développement), TA70/01,

Avenue Agropolis,

34398 Montpellier Cédex 5, France

<clavel@cirad.fr>

${ }^{2}$ Laboratoire d'écophysiologie moléculaire, UMR 137 Biodiversité des sols,

Faculté de sciences et technologie,

Université Paris 12,

64 Avenue du Général de Gaulle,

94010 Créteil Cédex, France

${ }^{3}$ ISRA/CERAAS

(Centre d'étude régional pour l'amélioration

de l'adaptation à la sécheresse)

CERAAS, BP 3320, Thiès-Escale,

Thiès, Sénégal

\begin{abstract}
Drought is a multiform constraint expressing at different plant organisation levels. It is recognised as the first factor limiting the agriculture production in the world. The Sahel subtropical regions were the most exposed to the devasting effects of the recent climate change. A state of knowledge referring to the plant responses to drought is a fundamental initial step to any program of selection. This review concerns more particularly groundnut (Arachis hypogaea L.), which is a very common legume in the Sahel areas. Critical evaluations of traits as relevant selection criteria for a breeding program aiming at improving yield and yield stability under drought constraint were made. The genetic specificities of the species are exposed in the first part. Then a detailed description of the grain-legume traits related to drought adaptation is presented. The review was widened to other plants for the molecular responses to water deficit, supposed to be more general. Finally, the last part supplied an updated synthesis of the recent advances in biotechnology on groundnut with special focus on drought tolerance.
\end{abstract}

Key words: drought adaptation, groundnut, leguminous, selection criteria, physiological and molecular responses

L'arachide est cultivée sur près de 25 millions d'hectares, dans l'ensemble de la zone tropicale mais aussi en zone tempérée, jusqu'à $40^{\circ}$ de latitude Nord, aux États-Unis et en Chine. Sa remarquable plasticité face aux températures et aux besoins en eau explique l'extension de sa culture dans ces zones marginales, où les étés chauds lui permettent d'achever son cycle [1].

Au Sénégal, l'arachide (Arachis hypogaea L.) constitue la principale source de revenus agricoles et concourt largement à l'alimentation humaine et animale. Elle est cultivée sur près d'un million $\mathrm{d}$ 'hectares. Dans ce pays, la culture de l'arachide est établie depuis un siècle dans les zones les plus sèches (zones sahélienne et soudano-sahélienne) qui sont aussi les plus touchées par les changements climatiques récents qui ont abouti à une spectaculaire « avancée du désert » (figure 1). Au niveau de ces aires de culture, aucune autre espèce agricole, pas même le mil ni, a fortiori, le sorgho, n'est en mesure de générer une quantité de matière sèche à l'hectare aussi importante. La parfaite adéquation de la plante aux sols très sableux de cette région, l'intégration naturelle de cette légumineuse dans une alimentation basée sur les céréales, de même que dans la rotation culturale et ses utilisations très variées sont les atouts majeurs de cette culture dans les pays sahéliens. La sécheresse est largement reconnue comme le premier facteur limitant la production agricole mondiale [2-4]. Globalement, $35 \%$ de la superficie cultivable peut être classée comme aride ou sub-aride et, sur ce qui reste, $25 \%$ des superficies au moins sont régulièrement soumises à des périodes de sécheresse [5]. De plus, les zones touchées sont en progression car l'un des dangers majeurs et avéré de "l'effet de serre » est l'élévation des températures qui accroît les risques de sécheresse. La bonne gestion de la ressource en eau est donc une nécessité économique et écologique [6]. En Afrique, où la culture pluviale est très largement majoritaire, la sécheresse est une contrainte permanente de la production agricole [7]. Depuis les changements climatiques intervenus au début des années soixante-dix, le problème se pose de manière particulièrement aiguë en termes d'alimentation voire de survie des populations rurales des régions subsahariennes. L'approche scientifique la mieux à même d'accroître l'adaptation des plantes à la sécheresse n'est pas clairement définie au niveau de la recherche agronomique. Les choix méthodologiques des 
chercheurs dépendent beaucoup du contexte socioculturel dans lequel ils évoluent [5]. On peut, par exemple, se situer au niveau de l'amélioration d'un système de culture ou bien au niveau de la transformation moléculaire de la plante, deux options très différentes du point de vue des contextes agricoles et technologiques nécessaires à la réalisation des objectifs. Cependant, si la demande sociale est forte, comme en Afrique ou en Australie, on choisi le plus souvent $d^{\prime}$ améliorer une espèce particulière car le transfert de la technologie - la semence améliorée d'une espèce connue et déjà utilisée - sera rapide et efficace. Un certain nombre de points font néanmoins l'objet d'un consensus scientifique. Le raccourcissement des cycles de culture pour les adapter à la longueur de la saison des pluies, méthode classique très utilisée par les sélectionneurs, est aujourd'hui encore probablement la méthode la plus efficace pour améliorer les rendements [8-10]. Par ailleurs, les sélections pour le seul rendement (ou ses composantes) en conditions de déficit hydrique sont toujours largement pratiquées mais ont montré leurs limites [10]. Cependant, le rendement et ses composantes sont fortement influencés par les facteurs environnementaux [11]. En outre, plus les facteurs d'alimentation hydrique et de fertilité des sols sont limitants, plus la variabilité spatiale et interannuelle des réponses variétales est forte car, dans ces conditions, la variance génétique et l'héritabilité des caractères liés au rendement sont encore plus faibles que dans un environnement favorable [12]. Cette forte variabilité des réponses entraine des interactions génotype $x$ environnement très importantes en milieu sec [13] qui grèvent les résultats de sélection.

En ce qui concerne les approches basées sur la physiologie, d'autres limitations sont constatées. Les caractères physiologiques sont rarement étudiés sur le plan de leur signification fonctionnelle dans l'élaboration du rendement [14]. On a observé par ailleurs que les traits qui contrôlent le développement de la plante et de la culture, essentiels pour assurer un bon rendement sous contrainte hydrique, sont rarement liés au statut hydrique des plantes [4]. Les études purement physiologiques qui ne mettent en œuvre qu'un ou deux génotypes sont bien souvent impuissantes à aider le sélectionneur car elles ignorent la variabilité génétique du caractère étudié. Les études conduites au champ dans un environnement mal contrôlé distinguent rarement les caractères intrinsèques (constitutifs) des caractères adaptatifs (induits par le stress) mais celles qui sont conduites en laboratoire ignorent la plasticité des réponses phénotypes qui est essentielle dans l'adaptation. Si une gamme de variétés est étudiée, les informations utilisables en sélection seront plus nombreuses mais bien souvent les méthodologies de criblage seront complexes et donc difficiles à utiliser sur un grand nombre de génotypes $[10,15]$. Dans le cas où la physiologie se pratique au niveau moléculaire, on cherche en général à identifier un gène dont le rôle serait essentiel dans la « résistance » à la sécheresse. Si, contrairement au principe émis par Passioura [14], on établit que la présence de ce caractère moléculaire (enzyme-clé) est lié à un bon rendement en conditions sèches alors l'apport pour la sélection sera fondamental. Malheureusement aucune application concrète en agriculture n'étaye cette hypothèse. En effet, de la même manière qu'il n'existe pas un gène unique responsable du rendement, il est probable qu'il n'y a pas de contrôle génétique simple de ce même rendement en conditions de déficit hydrique [8]. Depuis une décennie environ, l'intégration pluridisciplinaire est régulièrement prônée mais reste difficile à réaliser car les ressources humaines et techniques à réunir sont multiples. Par conséquent, la sélection pour l'adaptation à la sécheresse reste donc un défi pour le sélectionneur [7, 10, 15], car il lui faut généralement choisir parmi un grand nombre de caractères et de méthodes de mesure souvent lourdes ou inopérantes si on les considère individuellement.

Un état des connaissances dans le domaine complexe de l'adaptation à la sécheresse des plantes est une étape initiale fondamentale à tout programme de sélection. C'est ce que nous proposons dans cet article plus particulièrement sur une légumineuse très cultivée dans les aires subsahéliennes, I'arachide (Arachis hypogaea L.). Les particularités génétiques de l'espèce cultivée seront exposées dans une première partie. Puis la description des facteurs d'adaptation des légumineuses à la sécheresse sera présentée. Ces facteurs seront analysés en fonction de leur utilisation potentielle comme critères de sélection pour améliorer le rendement en condition de sécheresse. Le bilan des connaissances proposé sera élargi à d'autres espèces dans le cas des résultats récemment obtenus sur les mécanismes moléculaires de résistance supposés plus généraux. La dernière partie fournira une synthèse actualisée des avancées récentes en biotechnologies sur l'arachide.

\section{Présentation de l'espèce}

\section{Mode de reproduction de l'espèce cultivée}

L'arachide est une plante fortement autogame. Les fleurs sont de couleur jaune à jaune orangé de type papilionacé-cléistogames. Cependant, le taux d'allogamie de l'arachide n'est pas nul et peut varier de 0,2 à 6,6\% selon les types botaniques, les variétés, les localités et les insectes pollinisateurs présents. Après la fécondation, la base de l'ovaire s'allonge à travers les pièces florales pour donner naissance à un prolongement à structure de tige, le gynophore, qui pointe vers le sol et contient les ovules fécondés à son extrémité. Le gynophore s'enterre verticalement tandis que le fruit ou gousse en formation prend une position horizontale entre 2 et 7 centimètres sous la surface du sol (figure 2).

Une plante peut émettre de 600 à 1000 fleurs selon son cycle, mais la proportion de fleurs produisant des gynophores et des fruits est réduite, de l'ordre du dixième, et variable dans le temps. En effet, les fleurs écloses tardivement ne disposent plus du temps suffisant pour donner des fruits mûrs. On distingue ainsi une période de floraison utile, très brève en régions subsahélienne, au-delà de laquelle les produits formés n'arrivent pas à maturité.

\section{Diversité génétique de l'arachide}

La floraison et la croissance de l'arachide sont indéterminées et sa distribution géographique importante. La plasticité et la diversité morphologique de l'arachide sont, par conséquent, très fortes. Le port de la plante peut être érigé ou rampant, avec tous les stades intermédiaires. On distingue plusieurs types variétaux, principalement sur la base de leur système de ramification, notamment de la fréquence des ramifications d'ordre élevé et de la disposition relative des rameaux végétatifs et des

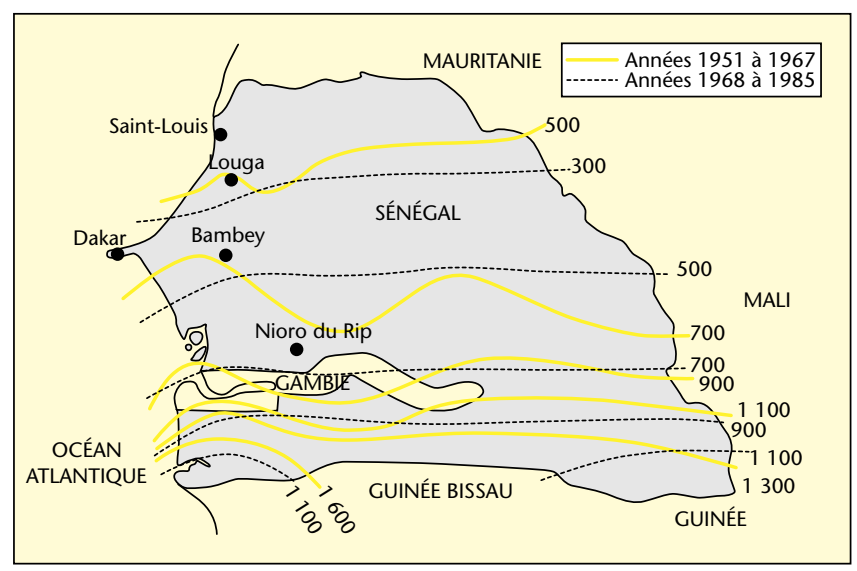

Figure 1. Evolution des isohyètes moyens ( $\mathrm{mm}$ ) au Sénégal durant la période 1951. 1985 (source : service de bioclimatologie de l'ISRA). 


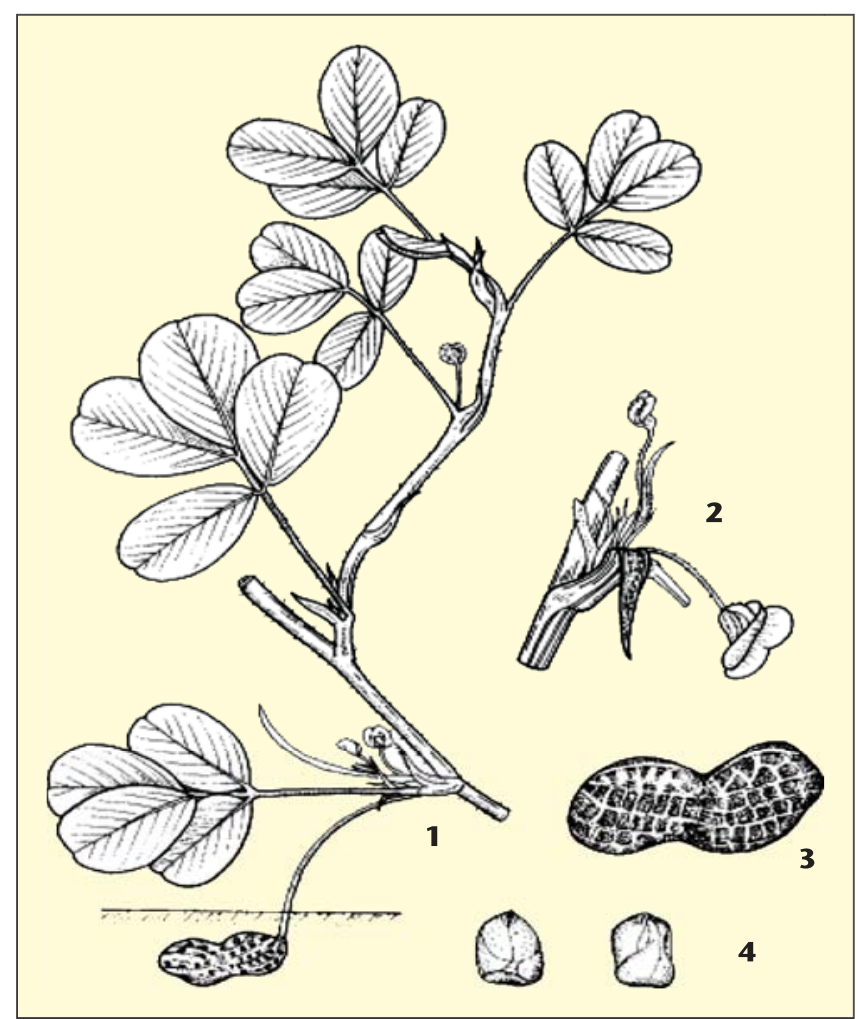

Figure 2. Représentation schématique d'un rameau de Arachis hypogaea L. 1) Rameau secondaire fructifère (portant une inflorescence, une fleur, un gynophore et un fruit) et un rameau végétatif ; 2) Inflorescence ; 3) Fruit (gousse bigraines) ; 4) graines.

rameaux reproducteurs [16]. Bunting [17] a ainsi défini deux groupes: I'un à ramification alternée, l'autre à ramification séquentielle (tableau 1). Les différents types de cultivars (variétés commercialisées) - Virginia, Spanish et Valencia - s'inscrivent aisément dans la classification botanique de l'espèce mais ils excluent une partie de la variabilité des Fastigiata représenté par les variétés botaniques aequatoriana et peruviana (tableau 1).

Les programmes d'élargissement de la base génétique des cultivars, notamment au moyen de la sélection de population [18], sont rares. La sous-utilisation des ressources génétiques de l'arachide par les sélectionneurs s'explique par le fait que les espèces sauvages du genre Arachis (Arachis spp.) en général diploïdes ne sont pas directement compatibles en croisement avec $A$. hypogaea $\mathrm{L}$. et par la difficulté des interfécondations artificielles sur l'arachide. Une population de ce type a été cependant développée au Sénégal par sélection récurrente $[19,20]$. L'objectif

Tableau 1. Classification botanique de l'arachide cultivée (Arachis hypogaea L.) tétraploïle (d'après Singh et Simpson, 1994 et Herselman, 2003).

\begin{tabular}{|lcccc|}
\hline Sous-espèce & $\begin{array}{c}\text { Variété } \\
\text { botanique }\end{array}$ & $\begin{array}{c}\text { Type } \\
\text { commercial }\end{array}$ & Ramification & Port \\
\hline Hypogaea & hypogaea & Virginia & alternée & $\begin{array}{c}\text { rampant } \\
\text { à érigé } \\
\end{array}$ \\
& hirsuta & $\begin{array}{c}\text { Peruvian } \\
\text { Runner }\end{array}$ & alternée & rampant \\
& fastigiata & $\begin{array}{c}\text { Valencia } \\
\text { Fastigiata }\end{array}$ & séquentielle & érigée \\
& vulgaris & Spanish & séquentielle & érigée \\
& aequatoriana & - & & \\
& peruviana & - & & \\
\hline
\end{tabular}

de ce programme était d'élargir la base génétique afin de rassembler des allèles favorables à la résistance à la sécheresse. Par ailleurs, certains programmes du Brésil, centre d'origine de l'espèce, et des États-Unis ont développé des amphidiploïdes synthétiques d'arachides sauvages, natives du Brésil et de Bolivie, et des hydrides entre des espèces sauvages et l'arachide cultivée dans le même objectif [21]. Du fait de leur richesse potentielle en gènes de résistance, ces espèces sauvages de l'arachide font actuellement l'objet d'une grande attention et notamment d'analyse de diversité moléculaire à l'aide de marqueurs $\operatorname{RAPD}[22,23]$.

\section{Adaptation des légumineuses au déficit hydrique}

Dans cette section, il sera fait une revue des caractères utilisables pour améliorer l'efficacité de la sélection pour l'adaptation à la sécheresse suivant deux approches. La première approche correspond au cadre d'étude décrit par Kramer [24], Levitt, [25], puis Turner [2, 26] sous I'appellation de Drought Resistance Framework. Elle identifie classiquement trois grands types de mécanismes: I'esquive (drought escape), l'évitement (avoidance ou dehydratation postponement) et la tolérance (dehydratation tolerance). Chacun des grands mécanismes décrits dans cette classification est sous la dépendance d'un certain nombre de caractères plus ou moins complexes et plus ou moins faciles à identifier. L'intérêt pour la sélection variétale d'une recherche cognitive sur les réponses des plantes au niveau des organes, des cellules et des molécules est incontestable [27]. Cependant l'amélioration individuelle des caractères associés à l'adaptation ne conduit pas toujours à des rendements augmentés en conditions de déficit hydrique [10,28].

La sélection, pour être efficace, doit s'opérer en priorité sur les caractères dont la «valeur » (pour l'élaboration du rendement) est forte relativement à d'autres caractères de résistance [8]. C'est la base de la deuxième approche appelée Yield Component Framework. L'indice de récolte et les caractères affectant l'efficience l'utilisation de I'eau par la plante [26, 29, 30] ont été identifiés comme les facteurs principaux d'un modèle d'élaboration du rendement en condition de déficit hydrique. Le Yield Component Framework décompose le rendement en composantes physiologiques théoriquement indépendantes, chacune intégrant des processus complexes. Ce modèle est élaboré à partir de la relation générale suivante entre le rendement et ses composantes:

$$
\mathrm{Y}=\mathrm{TDM} \times \mathrm{HI}
$$

où TDM représente la matière sèche totale (en général il s'agit des feuilles, tiges et graines car les racines sont rarement mesurées) et $\mathrm{HI}$, l'indice de récolte.

À partir de l'équation (1), une équation conceptuelle a été proposée par Passioura [29] en 1977 :

$$
Y=W \times W U E \times H I
$$

où W représente la quantité d'eau évapotranspirée par la culture et WUE, I'efficience de I'utilisation ou Water Use Efficiency (en unités de matière sèche produite par unité d'eau consommée par la culture).

Considérant que la matière sèche était davantage conditionnée par l'eau transpirée que par l'eau évaporée par le sol, Fisher [30] propose une réécriture de l'équation (2) comme suit :

$$
Y=T \times T E \times H I
$$

où T est la transpiration et $\mathrm{TE}$, son efficience (en unités de matière sèche produite par unité d'eau transpirée).

Ainsi, un certain nombre de travaux, réalisés principalement sur les céréales $[10,11,15,31,28]$ ont exploré l'utilisation plus ou moins combinée de ces deux approches pour la sélection. Ce chapitre analysera 
Tableau 2. Les principaux caractères impliqués dans les trois grands mécanismes $d u$ "drought-resistance-framework », leur utilité et leur facilité d'utilisation pour la sélection (d'après Turner et al., 2001).

\begin{tabular}{|c|c|c|}
\hline Mécanisme & Utilité & $\begin{array}{l}\text { Facilité de } \\
\text { sélection }\end{array}$ \\
\hline \multicolumn{3}{|l|}{ Esquive } \\
\hline Phénologie & Très haute & Facile \\
\hline Plasticité de développement & Haute & Facile \\
\hline \multicolumn{3}{|l|}{ Evitement de la déshydratation } \\
\hline Contrôle stomatique & Haute & Difficile \\
\hline$A B A$ & Discutable & Difficile \\
\hline Ajustement osmotique & Fonction des espèces & Difficile \\
\hline Développement racinaire & Haute & Très difficile \\
\hline \multicolumn{3}{|l|}{ Tolérance à la déshydratation } \\
\hline Stabilité membranaire & Haute & Facile \\
\hline Potentiel hydrique létal & Haute & Difficile \\
\hline Proline & Discutable & Facile \\
\hline
\end{tabular}

la pertinence des caractères proposés comme critères de sélection sur les légumineuses dans l'objectif d'améliorer le rendement en conditions de sécheresse. La présentation de cette analyse sera structurée selon le découpage proposé par Turner [10] en Drought Resistance Framework et Yield Component Framework.

\section{Mécanismes de résistance et critères de sélection}

Ces mécanismes décrits dans le Drought Resistance Framework sont les mêmes pour toutes les espèces végétales. Cependant, la variabilité génétique qu'ils présentent est dépendante de l'espèce. Or, la question de la variabilité génétique est centrale pour un programme de sélection intraspécifique. Certains caractères comme le développement racinaire et la régulation stomatique ont une valeur adaptative universelle, $d^{\prime}$ autres comme l'accumulation d'ABA ou de proline [32] paraissent présenter moins d'intérêt, d'autres encore comme l'ajustement osmotique semblent varier beaucoup moins chez les légumineuses que chez les céréales [33]. Les principaux caractères impliqués dans les trois grands mécanismes principaux de l'adaptation à la sécheresse, leur efficacité pour améliorer le rendement (" valeur ») et leur facilité d'utilisation pour la sélection des légumineuses sont résumés dans le tableau 2. Les principales observations expérimentales ayant conduit à cette synthèse font l'objet des paragraphes qui suivent.

\section{L'esquive}

L'esquive permet à la plante de réduire ou d'annuler les effets de la contrainte hydrique par une bonne adéquation de son cycle de culture à la longueur de la saison des pluies. La variabilité génétique pour la longueur de cycle est généralement importante dans les plantes et plus particulièrement chez les espèces à floraison indéterminée comme l'arachide. Le rendement de nombreuses variétés a été amélioré grâce au raccourcissement des longueurs de cycle (précocité) et ceci chez pratiquement toutes les espèces cultivées annuelles [10], sur les légumineuses [33], comme sur les céréales $[9,13]$.

Ce mécanisme est particulièrement efficace dans les environnements avec déficits hydriques fréquents en fin de cycle, schéma habituel dans les pays sahéliens. L'arachide cultivée dans ces régions est affectée par une sécheresse qui correspond habituellement à la phase de remplissage des gousses [34,35]. Or, sur cette espèce, la réduction de rendement la plus importante a lieu lorsque la sécheresse intervient pendant cette phase [36]. En outre, lorsque le stress intervient pendant le remplissage des gousses, il affecte particulièrement certains processus physiologiques et biochimiques conditionnant la qualité de l'arachide [37]. Le développe- ment de variétés d'arachide qui supportent mieux le déficit hydrique pendant la phase finale du développement des gousses est donc un objectif de recherche important pour ces zones [38, 35]. Pour le Sénégal, le calcul des nouvelles longueurs de cycles souhaitables compte tenu de la nouvelle configuration climatique a précédé la mise en place d'une stratégie de sélection basée sur la réduction de la longueur de cycle [38]. Ces sélections ont permis d'améliorer très significativement les rendements de l'arachide pour les régions touchées par une réduction de la durée de l'hivernage [20,35,39]. Cependant, les sélections de variétés à cycles courts ne permettent pas toujours d'améliorer les rendements dans le cas où le déficit hydrique a lieu aussi en cours de cycle [40]. Par ailleurs, la réduction de la variabilité entrainant une réduction de la plasticité phénologique, elle est considérée comme une stratégie risquée dans le cas des légumineuses à floraison et à croissance déterminée [10]. Ainsi, on recherche aujourd'hui des variétés bien adaptées au niveau phénologique mais capables également de mettre en œuvre des mécanismes d'évitement et de tolérance.

\section{L'évitement}

Trois grands types de réponses permettent à la plante d'éviter ou, plus exactement, de retarder la déshydratation de ses tissus [10]. Ce mécanisme est appelé « évitement », en anglais avoidance ou parfois dehydratation post-ponement. Le premier groupe de caractères est lié à l'efficacité de l'extraction de l'eau du sol par les racines. L'aptitude des racines à exploiter les réserves en eau du sol sous stress est une réponse particulièrement efficace pour l'élaboration de la production de graines [29]. Le deuxième type de réponse est constitué par la régulation de l'ouverturefermeture des stomates, il conditionne les échanges entre $\mathrm{CO}_{2}$ et $\mathrm{H}_{2} \mathrm{O}$ et par conséquent la croissance et la productivité des cultures [28, 31]. Le troisième correspond à l'ajustement osmotique que les plantes réalisent en réponse au déficit hydrique [2]. Lorsque le potentiel hydrique foliaire décroît, le potentiel de turgescence et la conductance stomatique sont maintenus grâce à une accumulation intracellulaire de solutés permis par ce mécanisme. La pertinence des caractères correspondant à ces réponses pour la sélection sera discutée pour chacune des trois formes d'évitement définies.

- La capacité d'extraction de l'eau par le système racinaire

Un système racinaire capable d'extraire l'eau du sol est un trait essentiel pour la résistance à la sécheresse. Cette caractéristique revêt une importance particulière sur les cultures qui subissent régulièrement des déficits hydriques de fin de cycle $[19,33]$. Son impact sur le rendement est particulièrement élevé car elle intervient directement dans l'efficience de I'utilisation de l'eau en conditions de stress, un des trois termes de l'équation de Passioura [29]. La majorité des résultats reportés montre une corrélation positive entre la profondeur d'enracinement et le rendement en grain notamment sur l'arachide [41, 42].

Cependant, deux types de raisons limitent beaucoup I'utilisation des critères racinaires par les sélectionneurs [10]. L'impraticabilité du criblage au champ pour cette caractéristique sur une grande échelle et la difficulté de corréler des observations au champ à celles qui sont faites en pots. L'absence d'une compréhension précise du rôle exact des racines en conditions de ressources hydriques limitées [43] est un autre facteur limitant à la mise en place d'un système de criblage économe et efficace. Quelques exceptions, notamment au Sénégal [44], ont été fournies dans le cas très spécifique des sols très sableux et de texture homogène de la surface jusqu'en profondeur, sur lesquels poussent les arachides dans cette région. Dans ce cas, en effet, une bonne corrélation a été trouvée entre les mesures d'élongation racinaire en rhizotrons et celles réalisées au champ grâce à un dispositif d'injection d'herbicide en profondeur. D'autres techniques utilisant la mesure de la force d'extraction de l'eau à I'aide de tensiomètres ou de la fluidité de la sève ont été suggérées [33, 45] mais jamais utilisées en sélection. 


\section{- La régulation stomatique}

Située à l'interface entre l'intérieur (plus ou moins turgescent) et l'extérieur (plus ou moins sec) des tissus foliaires, les stomates jouent un rôle fondamental dans la régulation des pertes en eau de l'appareil foliaire. La régulation de l'ouverture-fermeture des stomates dépend du potentiel hydrique foliaire et de l'humidité de l'air au champ [31]. Une faible conductance conduit à une fermeture des stomates rapide en conditions de déficit hydrique. Les génotypes à faible conductance sont plus sensibles au déficit de vapeur et à la baisse du potentiel hydrique foliaire que les génotypes à forte conductance. Une faible conductance est généralement proposée comme un trait favorable à l'adaptation à la sécheresse (Jones, 1979, 1980, 1987 ; Turner 1979, 1982, 1986, cités dans [28]). Cependant la fermeture stomatique réduit I'assimilation du $\mathrm{CO}_{2}$ et conduit inévitablement à une réduction de l'activité photosynthétique. En conséquence, l'intérêt d'une réponse stomatique plus ou moins rapide au déficit hydrique résulte d'un compromis entre la réduction de I'assimilation du $\mathrm{CO}_{2}$ et la nécessité d'éviter la déshydratation [28].

Des différences intervariétales existent chez les légumineuses. Elles ont notamment été montrées sur le niébé [46] et l'arachide [37, 47]. La mesure de la conductance stomatique et de la transpiration par porométrie exige une homogénéité parfaite des conditions environnementales incompatible avec les mesures sur un grand nombre de génotypes au champ. L'évaluation des réponses des stomates par porométrie n'est donc généralement pas retenue par les sélectionneurs pour le criblage de génotypes $[10,48,49]$. L'élévation de température résultant de la fermeture des stomates peut être appréciée sur un grand nombre de lignées au champ par téléthermométrie en utilisant un thermomètre à infrarouge. Mais là encore, la validité des mesures est soumise à l'homogénéité des conditions environnementales, notamment la présence de vent et la densité du couvert, difficile à obtenir en conditions de déficit hydrique [10].

Sur les céréales, la fermeture des stomates est contrôlée par un signal hormonal, I'acide abscissique ou ABA en réponse à l'assèchement du sol [50]. Mais les sélections réalisées sur l'accumulation de l'ABA dans les céréales n'ont pas conduit à une amélioration du rendement [51]. Chez les légumineuses, les travaux publiés sur l'intervention de l'ABA ne concernent que le lupin [52]. Sur l'arachide, il semble que le potentiel hydrique et la fermeture stomatique soient en liaison directe $[47,53]$.

- L'ajustement osmotique

Ce mécanisme permet de maintenir la conductance stomatique et la photosynthèse à des potentiels hydriques bas, il intervient aussi en retardant la sénescence foliaire et en améliorant l'extraction de l'eau par les racines [10,31, 54]. Le niveau d'ajustement osmotique réalisé par les légumineuses est modeste comparé à celui des céréales [33]. La variabilité génétique présente a été utilisée pour sélectionner des lignées de blé et de sorgho [28,55]. Ce n'est pas le cas chez les légumineuses bien qu'il semble y avoir une variation relativement importante chez l'arachide [41]. Cette variabilité n'a pas été retrouvée dans la gamme des variétés à phénologie relativement comparables cultivées au Sénégal $[34,56]$. $C^{\prime}$ est une limitation majeure pour la prise en compte de ce caractère pour la sélection des légumineuses.

\section{La tolérance}

- Stabilité des membranes cellulaires

En réaction à une limitation hydrique, la plante limite l'extension de son feuillage, accroît la profondeur de son enracinement. Une fermeture plus ou moins précoce des stomates s'opère afin de réduire les pertes en eau de la plante par transpiration. Cette régulation stomatique conditionne le statut hydrique des feuilles qui restent turgescentes si les stomates se ferment très vite. Le mécanisme de tolérance des membranes cellulaires s'exprime lorsque ces dispositifs périphériques de protection des cellules ne sont plus efficaces. Le caractère de tolérance sensu stricto le plus connu est la résistance membranaire ou résistance protoplasmique. Elle est le plus souvent mesurée par la méthode des efflux d'électrolytes après choc osmotique au polyéthylèneglycol $[10,57]$. La tolérance membranaire s'exprime à un niveau particulièrement important chez les plantes dites de résurrection qui peuvent reconstituer leurs membranes après des périodes de plusieurs semaines de déshydratation [58].

Chez les céréales, l'existence d'une relation entre dégâts membranaires et tolérance à la sécheresse semble dépendre des génotypes utilisés. Non montrée initialement sur blé [11], elle a été observée sur les réponses de croissance et la productivité au champ de variétés de blé dur [59]. L'hypothèse que les plantes résistantes à la sécheresse au niveau cellulaire sont souvent capables de garder leurs stomates ouverts et ont donc un fort potentiel d'assimilation du $\mathrm{CO}_{2}$ lors de sévères déficits hydriques a été émise lors d'une étude portant sur Phaseolus vulgaris [60]. On a aussi montré, sur le blé dur, que l'indice de dommage membranaire était corrélé non seulement à la croissance des plantules mais aussi à la performance des plantes au champ [59]. Les mêmes observations ont été réalisées sur le blé tendre [61] mais dans cette étude les variétés présentant la stabilité membranaire la plus élevée et la meilleure production en grain étaient celles qui montraient un potentiel hydrique foliaire élevé.

Une variabilité génétique importante de ce caractère existe chez les légumineuses notamment chez le pois chiche, le soja et l'arachide [62]. La forte capacité de tolérance de l'arachide a été soulignée [37, 63] ainsi que le fait qu'un des mécanismes majeurs mis en jeu était probablement le maintien de l'intégrité membranaire $[34,53]$. La détermination de la résistance protoplasmique à différents stades de développement de l'arachide a permis d'observer qu'elle s'accroissait avec l'âge des feuilles mais que les classements variétaux n'étaient pas changés [64]. Cette observation offre l'opportunité d'effectuer des criblages efficaces au stade jeune [53].

Au niveau moléculaire, un ralentissement du métabolisme protéique et une augmentation du catabolisme des protéines cellulaires en réponse à la contrainte hydrique ont été observés [65] sur Vigna unguiculata (niébé). Sur arachide, une relation entre le niveau de tolérance membranaire de différents cultivars et le niveau d'acyl-lipide des membranes a été mise en évidence [66]. Certaines enzymes hydrolytiques impliquées dans la réponse des plantes à la sécheresse ont été précisées. II s'agit d'acylhydrolases [67, 68], d'une ascorbate peroxydase [69] d'endoprotéases $[70,71]$ et de phospholipases [72]. Roy-Macauley [70] a montré qu'il existe une relation entre le déficit hydrique, le degré de sensibilité de la plante et les activités endoprotéolytiques chez les cultivars de $V$. unguiculata testés. La caractérisation de la nature des endoprotéases impliquées a permis de montrer que l'expression du gène de l'aspartyl protéase en conditions de déficit hydrique était plus faible chez les cultivars de niébé tolérants que chez les sensibles [71]. II apparaît donc probable que, sur le niébé (Vigna Unguilata L.), fabacée tropicale comme l'arachide, plus les plantes sont sensibles, plus les enzymes dégradatives sont efficaces. Ces dégradations conduisent à une destruction des membranes photosynthétiques, il s'ensuit un manque de photosynthats et une réduction de la croissance et du rendement. La plante s'autodétruit de façon plus ou moins régulée via diverses hydrolases pour mieux survivre au stress. Cette hypothèse est renforcée par de récents résultats sur la tolérance au stress de l'appareil photosynthétique obtenus grâce à I'utilisation de la fluorimétrie. En effet, la fluorescence chlorophyllienne émise par une feuille soumise à un stress environnemental est étroitement reliée à l'intégrité et à l'efficience du photosystème II (PSII) luimême situé sur les membranes thylacoidales [73]. II semble en outre que cette mesure soit très sensible aux différences entre génotypes et corrélée aux rendements obtenus $[74,75]$.

- Potentiel hydrique létal

Selon Sinclair et Ludlow [76], la valeur du potentiel hydrique que peut atteindre la dernière feuille viable (capable de récupérer après réhydra- 
Tableau 3. Potentiels hydriques létaux pour une gamme de légumineuses (d'après Turner et al., 2001).

\begin{tabular}{|c|c|c|}
\hline Espèces & $\begin{array}{c}\text { Potentiels hydriques } \\
\text { létaux }\end{array}$ & Références \\
\hline Niébé & $-1,8 \mathrm{MPa}$ & $\begin{array}{l}\text { Shakel et Hall (1883) } \\
\text { Sinclair et Ludlow } \\
(1986)\end{array}$ \\
\hline $\begin{array}{l}\text { Mungbean (Vigna } \\
\text { radiata) }\end{array}$ & $-1,9 \mathrm{MPa}$ & $\begin{array}{c}\text { Sinclair et Ludlow } \\
\qquad(1986) \\
\text { Flower et Ludlow (1987) }\end{array}$ \\
\hline Soja & $-5,0 \mathrm{MPa}$ & $\begin{array}{c}\text { Sinclair et Ludlow } \\
\text { (1986) } \\
\text { Flower et Ludlow (1987) }\end{array}$ \\
\hline Arachide & $-3,4$ à - 8,2 MPa & $\begin{array}{l}\text { Flower et Ludlow (1986, } \\
1987)\end{array}$ \\
\hline
\end{tabular}

tation de la plante) représente une mesure clef de la capacité de tolérance d'une plante. Cette valeur varie selon les espèces. Si l'on se réfère au tableau 3, l'arachide peut être considérée comme la légumineuse de grande culture la plus tolérante à la sécheresse. Certaines observations ont conclu que la tolérance à la déshydratation était reliée à la capacité d'ajustement osmotique [77] mais des études de QTL ont suggéré que d'autres facteurs que l'ajustement osmotique étaient associés dans la tolérance [78]. Compte tenu d'une capacité d'ajustement osmotique de I'arachide relativement faible, il est possible que les niveaux de tolérance membranaire et la faible valeur du potentiel hydrique létal soient liés. Peu de programmes de sélection ont fait appel à ce critère. Certaines études ont considéré le taux de survie de jeunes plantules mais les résultats obtenus n'étaient pas reliés à la survie des plantes à des stades plus tardifs ni à la production [10].

\section{Amélioration du rendement en condition de sécheresse}

Cette approche relevant du Yield-Component-Framework propose un modèle qui intégrerait en composantes du rendement les mécanismes de réponse à la sécheresse précédemment décrits. Le modèle de base est fourni par l'équation (3) présentée en introduction de ce chapitre. L'objectif recherché est d'améliorer le rendement en conditions de déficit hydrique. Les deux principaux intérêts de cette méthode sont d'une part qu'une analyse en composantes fonctionnelles intégratives permettra de mieux comprendre les raisons des performances génotypiques sous stress [10] et d'autre part qu'une sélection réalisée sur une réponse au déficit hydrique au niveau de la plante entière est plus efficace sur le rendement qu'une sélection portant sur un caractère simple plus difficile à relier à la production $[10,79]$. Cette approche permettrait de contourner les difficultés pratiques pour la mesure de certains caractères comme le système racinaire et la conductance stomatique sur de nombreux génotypes en utilisant des critères de substitution (surrogates), liés à ces caractères et utilisables en sélection. Cependant, l'existence de relations négatives entre les composantes fonctionnelles et les limitations des mesures de substitutions peuvent entraîner des échecs en termes d'amélioration de la production.

\section{Associations négatives entre les composantes physiologiques}

Dans de nombreuses situations, le TE et HI de l'équation (3) que nous rappelons ici :

$$
\mathrm{Y}=\mathrm{T} \times \mathrm{TE} \times \mathrm{HI}
$$

sont négativement corrélés. Un exemple est donné par l'arachide chez laquelle TE et HI sont liés via TDM (Total Dry Matter) qui représente la biomasse totale [80]. La part du poids des fanes dans TDM peut être élevée, ce qui entraîne un $\mathrm{HI}$ bas. Or, chez certaines variétés c'est une forte production de fanes qui affaiblit le $\mathrm{HI}$ alors que chez d'autres un $\mathrm{HI}$ élevé peut être dû à une faible proportion de fanes non associée à une forte production de gousses. Si on ne tenait compte que des composantes de l'équation (3), les lignées du premier type seraient écartées. Il est donc important de sélectionner en vue d'un HI élevé mais à condition que TDM soit constant. Des analyses dynamiques en termes de taux de croissance journalier $(C)$ et de répartition de la matière sèche entre les graines et les feuilles (partitioning coefficient, $p$ ) en tenant compte de la durée du cycle ont fait ressortir que les causes des variations de rendement chez l'arachide et le niébé étaient différentes : il semble que les arachides les mieux adaptées à la sécheresse aient un $p$ élevé et un C plutôt faible [81] alors que pour le niébé c'est un C élevé qui conditionne la production en condition de sécheresse [82]. Les explications physiologiques à ces différences sont inconnues [10] mais l'existence de stratégies d'adaptation différentes sur deux fabacées tropicales témoigne de la variété des réponses adaptatives dans l'élaboration du rendement. L'origine en partie physiologique de ces corrélations négatives peut être expliquée. En effet, si TE est apprécié en matière sèche produite par unité d'eau transpirée, la théorie prédit un accroissement de TE lorsque les stomates se ferment car le rôle premier de la fermeture des stomates est de limiter la transpiration. Cependant, dans les conditions de champ, l'augmentation de température due à la fermeture des stomates limite l'assimilation du $\mathrm{CO}_{2}$ soit directement [28] soit indirectement par les dégâts occasionnés au niveau des centres réactionnels (photosystèmes) de la photosynthèse [73]. Par conséquent, du fait de ces échanges $\mathrm{CO}_{2} / \mathrm{H}_{2} \mathrm{O}$ au niveau des stomates, une faible conductance possède un coût physiologique sur la production en terme d'efficience photosynthétique. II s'ensuit donc que si l'amélioration de TE ou WUE est obtenue par une fermeture précoce des stomates, les conséquences peuvent être négatives sur l'élaboration du rendement [28]. Cela semble être le cas sur l'arachide, chez laquelle une transpiration et conductance stomatique élevées ont été observées sur les variétés les plus productives en conditions de sécheresse $[49,83]$ alors que de telles observations n'ont jamais été réalisées sur le niébé.

\section{Utilisation de mesures de substitution}

Il est à l'heure actuelle quasiment impossible d'estimer et d'intégrer sur la durée d'un cycle les mesures de T et TE dans un programme de sélection. On cherche donc une estimation du TE de l'équation (3) par des mesures de discrimination isotopique du carbone $(\Delta)$ représentant le ratio de la pression interne et externe du $\mathrm{CO}_{2}$ [84]. Une corrélation négative a été observée entre TE et $\Delta[10,33,85]$ (on considère donc que les plantes présentant une faible $\Delta$ possèdent un fort TE $[86,87])$. Cependant $\Delta n^{\prime}$ est pas directement et négativement corrélée au rendement, au contraire, de nombreuses études ont montré une corrélation positive [86, 87]. Les mesures de TE et T de l'équation (3) étant inversement liées, la sélection indirecte pour TE via $\Delta n^{\prime}$ a pas réussi jusqu'à présent du fait de l'existence de ces liaisons complexes dont la nature, physiologique ou génétique, est inconnue [10]. L'hypothèse de la nature génétique des relations mises en évidence est actuellement testée dans un programme de sélection de I'arachide et du haricot, en Australie [88]. Les résultats actuels montrent que la liaison négative entre TE et T semble avoir été rompue par la sélection pratiquée sur un certain nombre de génotypes. Cependant, lors des évaluations en essais multilocaux, les nouvelles lignées d'arachide développées en utilisant les composantes du modèle n'ont pas présenté de rendements améliorés par rapport à celles qui avaient été sélectionnées sur le rendement directement (Dovkiw, communication personnelle). La recherche conduite actuellement en Australie vise à connaître les raisons de cette absence de différences qui pourraient être de nature technique (manque d'efficacité du $\Delta$ pour traduire TE) ou physiologique (rupture de la liaison entre TE et $\mathrm{T}$ très difficile). 


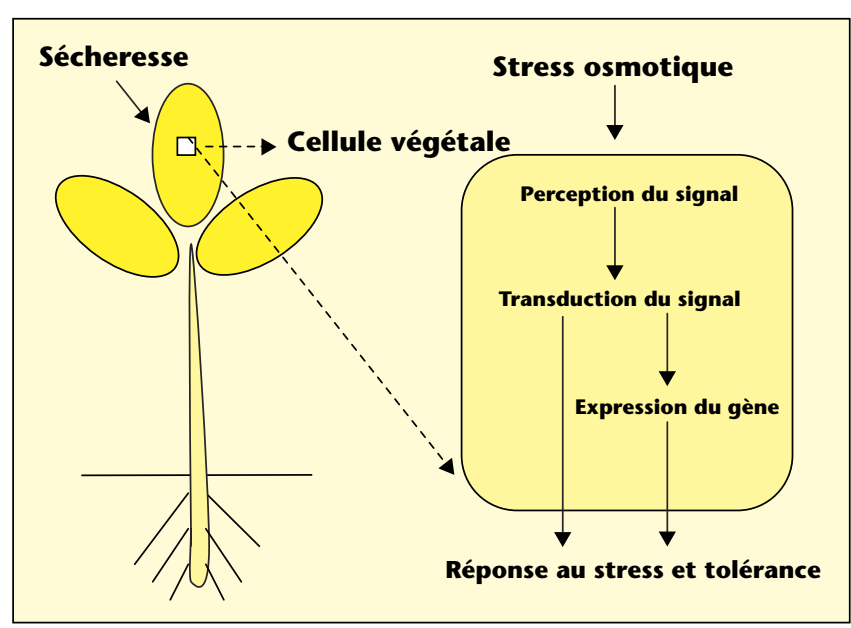

Figure 3. Représentation schématique des réponses moléculaires à la sécheresse dan une cellule végétale (d'après Yamaguchi-Shinozaki, 2002).

\section{Les mécanismes moléculaires de la réponse à la contrainte hydrique}

Ce chapitre concerne les résultats saillants récemment obtenus dans ce domaine toutes espèces confondues. Sur l'arachide, les biotechnologies, encore peu développées, font l'objet d'une présentation séparée. Comme les réponses adaptatives des plantes, les gènes induits par la sécheresse sont très variés et leur activation se révèle très complexe. Quelques applications des résultats de ces recherches dans les biotechnologies végétales (choix d'un gène candidat et transgénèse) viennent d'être réalisées. Cependant, elles ne concernent pas pour le moment le domaine agronomique c'est-à-dire la diffusion d'un cultivar transgénique à la fois productif et résistant à la sécheresse.

\section{Variété des fonctions des gènes induits par le stress osmotique}

Ces dernières années, un nombre important de gènes a été décrit comme répondant à la sécheresse au niveau transcriptionnel [89-91]. Les produits de ces gènes interviennent non seulement dans la tolérance au stress mais aussi dans la régulation de l'expression des gènes et dans la transduction des signaux de la réponse au stress [91] (figure 3). Ces produits de gènes induits par la sécheresse, ou, plus généralement, par le stress osmotique (stress hydrique, salin et du au froid) peuvent être classés en deux groupes : les protéines fonctionnelles et les protéines de régulation (figure 4). La première étape de l'activation de ces gènes correspond à la perception du signal émis lors de la déshydratation, elle est suivie par une cascade de messagers secondaires qui modifient la concentration du $\mathrm{Ca}^{2+}$ intracellulaire (figure 5). Différents récepteurs ou senseurs non spécifiques répondent à différentes contraintes abiotiques. Ils induisent tous une augmentation $\mathrm{du} \mathrm{Ca}^{2+}$ dans le cytoplasme, la production d'antioxydants [92] et une série de phosphorylations qui activent des protéines impliquées dans la protection cellulaire ou leurs facteurs de transcription. Par exemple, les voies d'activation des gènes codant pour des protéines de type LEA (Late Embryogenis Abundant) ont été trouvées sur certaines plantes très résistantes en réponse au stress hydrique $[90,93]$. L'activation des LEA pourrait représenter les voies de réparation des dommages [94]. La contrainte osmotique induit en particulier des changements dans la composition en phospholipides précurseurs de la production de messagers secondaires via les phospholipases (figure 5). La phospholipase D (PLD) par exemple est activée par la sécheresse [72]. Elle est impliquée dans une cascade de signaux conduisant à la fermeture des stomates [95]. L'existence de cette très grande

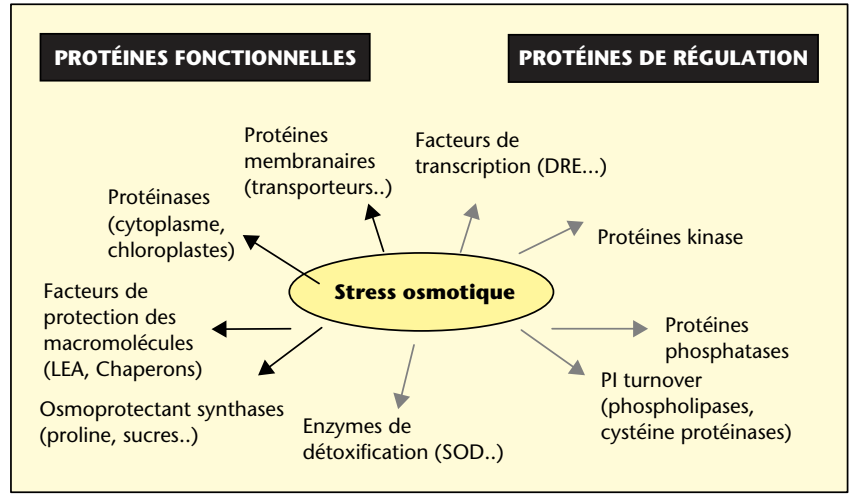

Figure 4. Gènes induits par le stress et leur fonction possible dans la réponse à la tolérance au stress osmotique (d'après Yamaguchi-Shinozaki, 2002).

variété de gènes induits par le stress osmotique suggère des réponses complexes au niveau de la plante [91].

\section{Activation transcriptionnelle des gènes}

De la même manière que les fonctions des gènes impliqués dans la réponse au stress sont très variées, l'activation de ces gènes est sous la dépendance de nombreux facteurs. L'acide absicissique (ABA) est produit sous l'influence du stress hydrique et son implication dans la modulation de la teneur en ARNm correspondant à nombreux gènes a été démontrée $[89,96]$. Les voies d'activation des gènes induits par la contrainte osmotique sont soit dépendantes soit indépendantes de l'ABA [96]. Les gènes induits par l'ABA sont souvent des protéines de type LEA ou déhydrine mais peuvent être aussi des gènes impliqués dans la synthèse des osmolytes, la perméabilité membranaire, le catabolisme ou la réparation cellulaire (figure 5). L'expression de tous les gènes de type LEA est régulée de façon transcriptionnelle et sous le contrôle de l'ABA [97]. L'induction des gènes non gouvernés par l'ABA est modulée par des facteurs de transcription dont les séquences, les plus connues sont de type DRE (Dehydration Responsive Element). Ces séquences ont été caractérisées et sont activées par le stress osmotique [98]. La surexpression des

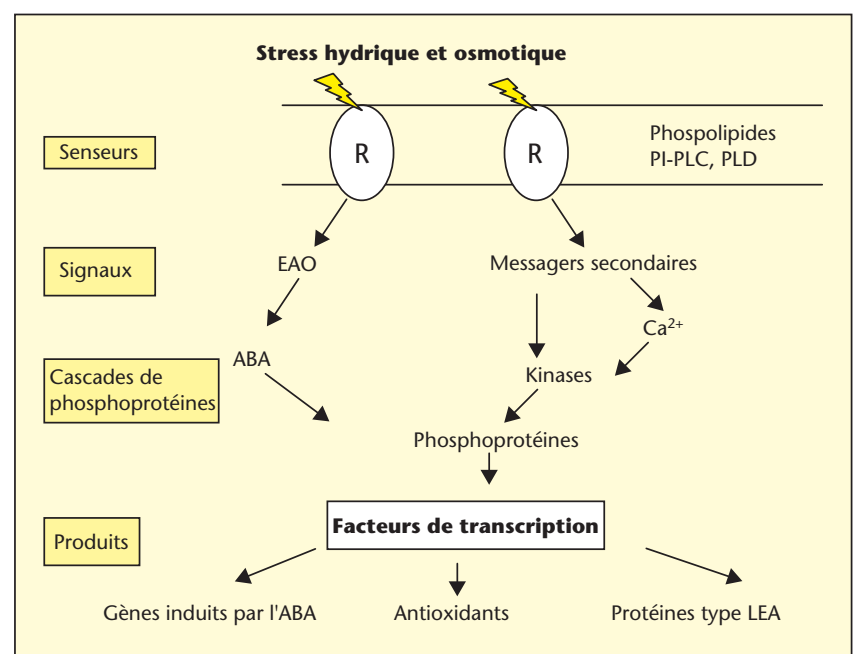

Figure 5. Représentation schématique des principales voies de signalisation majeures et principaux produits de transcription chez les plantes en réponse au stress osmotique. $R$ : récepteurs, EAO : espèces activées de l'oxygène, PI-PLC : phospholipase C, PLD : phospholipase D, ABA : acide abscissique, LEA : "Late Embryongenis Abundant", (d'après Diop, 2002). 
gènes codant pour des protéines de régulation de type DRE augmente la tolérance des plantes transgéniques correspondantes au froid, au sel et au déficit hydrique $[91,93,96]$. La régulation de ces gènes par certaines enzymes fortement impliquées dans le «turn over » des protéines comme la cystéine protéinase est donc importante pour la tolérance aux contraintes. Cependant, l'utilisation de ces gènes pour la transformation doit être considérée avec prudence car de nombreux métabolites sont produits par la plante en conditions de stress et des modifications sont possibles au niveau post-transcriptionnel et de la traduction [97].

\section{Lipides membranaires et contrainte hydrique}

La tolérance des membranes cellulaires face à la contrainte hydrique est I'un des mécanismes de résistance à la sécheresse les plus efficaces chez les plantes. II a été mis en relation avec la performance au champ des génotypes sur différentes espèces végétales notamment sur des légumineuses [59-61, 65] et sur l'arachide [53].

La destruction des membranes cellulaires est reflétée dans leur composition lipidique. Ainsi la contrainte hydrique induit une diminution de la teneur en phospholipides et du degré d'insaturation des acides gras, ce qui provoque une augmentation des acides gras saturés de type $\mathrm{C} 16: 0$ et $\mathrm{C} 18: 0$ et une « rigidification » des membranes cellulaires qui deviennent fragiles. Certaines enzymes impliquées dans la dégradation des phospholipides ont été identifiées. Ainsi les PLD représentent les principales enzymes responsables de la dégradation des phospholipides membranaires [67]. Cette activation de la PLD est réalisée indépendamment de I'ABA [99]. La quantification de la protéine correspondant à l'une d'entre elles a été réalisée [72]. Cette étude a montré que la contrainte hydrique induit la surexpression d'un gène de PLD et que les génotypes les plus tolérants possèdent la capacité de réprimer l'activation du gène en condition de stress. D'autres enzymes lipolytiques sont impliquées dans la réponse à la contrainte hydrique comme la phospholipases $C$ (PLC) qui génère deux messagers, le diacylglycerol et l'inositol, qui présentent plusieurs isoformes $[100,101]$. Le déficit hydrique sévère induit également une diminution du contenu en lipides polaires [102] Dans les feuilles, les galactolipides sont majoritairement impliqués dans cette réponse. L'une d'entre elles, homologue de la patatine, a été induite par le stress hydrique chez le niébé et son expression augmente en fonction de l'intensité du stress et du degré de résistance à la sécheresse [68].

\section{Endoprotéases et contrainte hydrique}

Les protéases (ou protéinases) de plantes interviennent aux différentes étapes de la vie de la plante comme la germination, le développement et la sénescence. Elles sont regroupées en cystéine, serine, metallo et aspartyl-protéinases en fonction de l'acide aminé occupant le site actif [103].

Les endoprotéases entrent en jeu dans de nombreux évènements comme la dégradation des protéines anormales, la mort cellulaire programmée $(M C P)$, le turn over des protéines, la dégradation des protéines de stockage des graines et la sénescence. La dégradation des protéines anormales participe à l'adaptation des plantes en conditions de contrainte environnementale [104]. La plupart des activités protéolytiques observées in vitro dans les extraits végétaux sont des protéases vacuolaires. Cependant les activités protéolytiques ont été mises en évidence dans les chloroplastes [70]. L'activité totale des protéases augmente durant la croissance de la plante et est activée par la contrainte hydrique, en particulier celle de l'aspartic protéinase [70, 71]. Cet accroissement de l'activité protéolytique sous la contrainte est plus fort chez les espèces sensibles comme le haricot que chez le niébé, plus résistant [71]. La MCP, appelée apoptose dans le cas des cellules animales, correspond à un mécanisme fondamental de la différenciation cellulaire par désintégration programmée de cellules particulières. Chez les plan- tes, les cystéines protéinases, protéases les plus connues, ont été principalement étudiées pour leur rôle important dans la réponse à l'attaque de pathogènes. Généralement, une synthèse d'inhibiteurs de protéases se produit de façon systémique suite à un stress biotique [105]. La blessure ou l'attaque est suivie par l'émission d'une cascade de signaux qui conduit à la production d'acide jasmonique [106] qui induisent à leur tour la production d'inhibiteurs de protéases [107]. Les cystéines protéinases constituent aussi les enzymes-clés de régulation de l'apoptose chez les animaux [108]. Dans le monde végétal, leur implication dans la MCP a été mise en évidence dans des suspensions cellulaires de tabac [109] et d'orge [110]. Les cystéines protéinases sont également activées dans le processus de dégradation des protéines de stockage durant la maturation. Elles ont été décrites chez différentes espèces végétales comme l'orge [111] ou le riz [112]. L'activité de ces enzymes est continuelle mais faible durant la vie végétale mais elles sont très impliquées dans le processus de sénescence. Une protéolyse accrue caractérise la sénescence génétiquement programmée des feuilles [113]. Au cours de cette phase, l'assimilation du carbone est remplacée par le catabolisme de la chlorophylle et des macromolécules dont les produits sont recyclés [114]. Le rôle des cystéines protéinases dans la dégradation des polypeptides foliaires endommagés sous l'effet de la contrainte [115] a été très étudié. Les transcrits de certaines cystéines protéinases s'accumulent en réponse à la contrainte hydrique $[116,117]$ et à l'ABA [115]. Le contrôle de l'activité protéolytique en cas de contrainte pourrait permettre de différer la sénescence. Ce contrôle passe notamment par le blocage de l'activité des cystéines protéinases par leur inhibiteur naturel, les cystatines [118]. L'accumulation des transcrits de cystatines a été observée en réponse au froid et à la salinité chez le riz [119] et le blé [120].

\section{Les biotechnologies de l'arachide}

Les réponses moléculaires des plantes à la sécheresse ont été présentées sur un plan général dans un précédent chapitre. Les travaux en biologie moléculaire sur l'arachide sont peu nombreux. Les principaux résultats concernent la régénération de la plante, étape indispensable de la transformation génétique (transgenèse). Ils ont été principalement réalisés aux États-Unis par le département d'horticulture de l'Université de Georgie. D'autres équipes travaillent dans ce domaine, notamment au département de botanique de I'Université de Caroline du Nord (ÉtatsUnis), à I'Institut de Biologie de l'Université Fédérale de Rio de Janeiro (Brésil) et à l'ICRISAT (International Crop Institute for the Semi-Arid Tropics, Hyderabad, Inde).

La synténie avec la plante modèle, Arabidopsis thaliana, est largement utilisée pour faire progresser les recherches dans ce domaine pour les dicotylédones. Depuis de nombreuses années, le riz s'est imposé à côté de $A$. thaliana comme plante modèle pour les céréales alors que les légumineuses (Fabacées) ne possèdent pas encore de plante de référence pour la génomique à part, peut-être Medicago trunculata. Pourtant elles représentent un des taxons végétaux les plus importants tant du point de vue de la biologie et de l'écologie fondamentales que du point de vue agronomique et environnemental [121]. Le niébé ou le pois chiche ont également été proposés pour ce rôle de légume modèle en ce qui concerne la réponse à la sécheresse [122].

\section{Les marqueurs de l'ADN}

Le marquage moléculaire de l'ADN a pour objectif de cartographier et de localiser les gènes en relation avec les caractères phénotypiques $d$ 'intérêt. Sur l'arachide, ce type de génotypage ne concerne que des fragments chromosomiques importants [123]. Or, pour que la sélection assistée par marqueurs (SAM) soit praticable, le génome doit être saturé avec des 
marqueurs uniformément espacés. De plus, l'établissement de liaisons fortes entre marqueur et caractère - inversement quantifiée par un déséquilibre de liaison faible - en garantie l'efficacité $[124,125]$. Cependant, I'arachide répond mal aux techniques de marquage de I'ADN [126, 127] alors que sa diversité morphologique est importante et le polymorphisme détecté par l'utilisation de marqueurs à l'intérieur des cultivars testés est faible $[127,128]$. Ce faible polymorphisme moléculaire est attribué à une polyploïdisation récente des génomes $A$ et $B$ (diploïdes) à l'origine de l'espèce cultivée tétraploïde [129] et au fait que les programmes de sélection n'ont utilisé qu'une faible partie de la variabilité disponible à I'intérieur de l'espèce cultivée [130]. On l'attribue aussi à une capacité de détection limitée de certains marqueurs moléculaires, comme les RFLP et les RAPD ou encore à l'utilisation d'un matériel végétal mal choisi [131, 132]. La technique AFLP (Amplified Fragment Lengh Polymorphism) en combinaison avec des enzymes de restriction de type EcoRI/Msel et Mlu/Msel s'est révélée plus efficace mais a confirmé le faible niveau de diversité génétique à l'intérieur de l'espèce cultivée [127]. À partir de cette technique, des marqueurs de type microsatellites (ou SSR pour Single Sequence Repeats) ont été développés. Ces microsatellites constituent à l'heure actuelle, les marqueurs les plus polymorphes à l'intérieur de l'arachide cultivée. Cependant, le pourcentage de détection de microsatellites, moins de $5 \%$ des clones testés, demeure très modeste au regard des résultats obtenus sur beaucoup d'autres espèces $[133,134]$. L'utilisation des espèces sauvages apparentées à l'arachide cultivée pourrait fournir un outil pour caractériser la variabilité génétique des collections du genre Arachis et contribuer à élargir la base génétique de I'espèce cultivée [21, 22]. Les RAPD (Random Amplified Polymorphic DNA), marqueurs dominants réputés instables mais faciles d'utilisation, ont récemment permis de retrouver les relations précédemment reportées sur la base d'observations morphologiques, cytologiques et de compatibilité en croisement des espèces [21].

La question de la faible liaison entre la grande diversité morphologique de l'arachide et sa diversité moléculaire réduite n'est pas résolue et l'absence de résultats concluants en matière de marquage moléculaire pose problème pour une espèce de cette importance. La diversification variétale initiale est pourtant considérable tant en Amérique du Sud [135, 136] et aussi dans les premiers foyers d'introduction en Asie, où subsiste probablement une forte variabilité exploitable. Par ailleurs, cette faible variabilité moléculaire est contredite par l'observation d'une grande diversité morphologique à l'intérieur de l'espèce cultivée [130, 137] dont seule une petite part de la variabilité contenue dans le germplasm disponible a été exploitée par la sélection moderne [18, 138]. À cet égard, le fait que la quasi-totalité des cultivars actuels dérivent seulement des deux variétés botaniques, hypogaea (Virginia) et vulgaris (Spanish) doit être souligné. Par conséquent, ce sont probablement l'histoire et les méthodes utilisées par la sélection moderne qui expliquent en grande partie ce défaut de diversité moléculaire constaté jusqu'à présent sur l'espèce cultivée.

\section{Génomique fonctionnelle et génie génétique}

Le marquage de I'ADN ne permet aucune interprétation sur l'action individuelle des gènes et de leurs interactions. En génomique fonctionnelle, en revanche, c'est la connaissance de la fonction de ces gènes et I'analyse de leur expression qui est visée. L'expression (ou transcrit) plus ou moins importante du gène est accessible à travers les changements d'ARNm eux-mêmes traduits en protéines, qui sont en général des enzymes dont la fonction métabolique est connue. L'objectif de ces études peut être la mise au point d'un test de réponse variétale ou bien, le plus souvent, $d$ 'inclure dans le génome de l'espèce cultivée des gènes intéressants. Ces techniques de génie génétique sont moins développées sur les légumineuses que sur les céréales [139]. En ce qui concerne l'arachide, les gènes ciblés sont des gènes contrôlant des maladies et la qualité de l'huile où des gènes de résistance à certains stress biotiques oligogéniques.

\section{Principales applications}

Les principales applications du génie génétique sur l'arachide concernent la transmission de certaines résistances biotiques et l'augmentation de la qualité de l'huile dont le contrôle génétique est simple. Les résistances plus complexes comme la résistance à l'aflatoxine ou à la sécheresse n'ont pas encore abouti à des applications concrètes. Ces aspects ayant déjà fait l'objet d'une revue [140], nous bornerons donc cet exposé aux dernières avancées en matière de tolérance à la sécheresse.

\section{Les dernières avancées en matière de tolérance à la sécheresse}

Les progrès réalisés sur la compréhension des bases moléculaires de la résistance à la sécheresse des plantes sont limités comparés à ceux qui ont été réalisés sur les stress biotiques [10]. Les produits des nombreux gènes activés par le stress interviennent non seulement dans la tolérance au stress mais aussi dans la régulation de l'expression des gènes et dans la transduction des signaux de la réponse au stress [91] ainsi que nous l'avons indiqué dans la partie 3. Par conséquent, comme en physiologie, il est difficile de distinguer les réponses constitutives des réponses adaptatives des plantes au niveau moléculaire. Chez l'arachide, espèce dont la capacité d'adaptation (plasticité individuelle) est très forte, cette difficulté pourrait être accentuée et les investigations moléculaires représentent un véritable challenge [10]. Dans le cas de certaines espèces comme le maïs $[141,142]$ ou le riz [143], on a pu relier la résistance à la sécheresse à des caractères quantitatifs (QTL) en utilisant un polymorphisme moléculaire au niveau de I'ADN. Cependant, cette stratégie ne peut être envisagée chez l'arachide du fait du faible polymorphisme des marqueurs ADN. La voie de la génomique fonctionnelle est actuellement explorée sur cette espèce. Des études récentes ont utilisé la RT-PCR et l'expression des gènes en réponse à la sécheresse sur l'arachide. La première étude [144] indique des différences moléculaires en termes de transcrits entre les plantes stressées et irriguées au niveau de certains gènes. Plus intéressant, les résultats montrent aussi qu'en condition de stress prolongé, certains transcrits ont été exprimés plus longtemps sur le génotype « résistant » que sur le génotype témoin mais aucune explication fonctionnelle $n$ 'est donnée et le type de résistance du génotype n'est pas défini. Dans la deuxième étude qui inclut également le maïs [145], la tolérance à la sécheresse est présentée comme la clef de la résistance à l'aflatoxine, ce qui n'est qu'une approche très globale puisque le raisonnement est basé sur des corrélations statistiques entre résistance à la sécheresse et résistance à l'aflatoxine sans que les mécanismes spécifiques soient décrits ni qu'une hypothèse fonctionnelle soit envisagée. L'étude indique toutefois que certains transcrits d'ARNm sont exprimés de façon différentielle en fonction du stress hydrique et notamment ceux d'une nouvelle phospholipase de l'arachide. L'objectif du travail conduit au Laboratoire d'écophysiologie moléculaire de l'Université Paris 12 est de déterminer l'expression des transcrits de trois gènes, sur l'arachide sous l'action $d^{\prime}$ 'une contrainte hydrique croissante. Les profils d'expression des gènes codant pour une phospholipase $D$, deux protéases et une LEA caractérisées sur trois cultivars d'arachide caractérisés au plan agronomique et physiologique et au niveau de la tolérance membranaire ont été étudiés. La Reverse-TranscriPtase Chain Reaction (RT-PCR) semi-quantitative a été utilisée afin d'établir une quantification relative des taux de transcrits correspondant à ces gènes sur les trois cultivars d'arachide au cours de la phase de déshydratation et après la réhydratation [146].

La deuxième partie de cette synthèse s'intéressera aux programmes de sélection conduits au Sénégal par le CIRAD et I'ISRA pour I'amélioration de l'adaptation à la sécheresse de l'arachide et aux résultats obtenus en matière de création variétale. 


\section{RÉFÉRENCES}

1. SCHILLING R. L'arachide. Paris, France: Maisonneuve et Larose, CTA Ed, 1996.

2. TURNER NC. Adaptation to water deficit: a changing perspective. Aust / Plant Physiol 1986; $13: 175-90$.

3. DAIE J. Mechanisms of drought induced alterations in assimilate partitioning and transport in crops. Crit Rev Plant Sci 1988 ; 7 : 117-37.

4. PASSIOURA JB. Drought and drought tolerance. Plant Growth Regul 1996 $20: 79-83$.

5. RUIVENKAMP G, RICHARDS P. Drought tolerance as a social process. In : Biotechnology and Development Monitor. Wageningen, Pays-Bas: CTA Ed, 1994 : 10-20

6. BOYER JS. Advances in drought tolerance in plants. Adv Agron 1996; 57 187-211.

7. CECCARELLI S, GRANDO S. Drought as a challenge for the plant breeder Plant Growth Regul 1996 ; 2 : 149-55.

8. BLUM A. Crop responses to drought and the interpretation of adaptation. Plant Growth Regul 1996 ; 20 : 135-48.

9. FUKAI S, PANTUWAN G, JONGDEE B, COOPER M. Screening for drought resistance in rainfed lowland rice. Field Crops Res $1999 ; 64: 61-74$.

10. TURNER NC, WRIGHT GC, SIDDIQUE KHM. Adaptation of grain legume to water-limited environments. Adv Agron 2001 ; 71 : 193-231.

11. BLUM A. Plant breeding for stress environments. Boca Raton, USA : CRC Press Ed, 1988.

12. MONNEUVEUX P, DEPIGNY-THIS D. Intégration des approches physiologiques génétiques et moléculaires pour l'amélioration de la tolérance à la sécheresse chez les céréales. In : Quel avenir pour l'amélioration des plantes? Paris, France : AUPELF-UREF Ed, 1995 : 149-63.

13. FUKAI S, COOPER M. Development of drought-resistant cultivars using physio-morphological traits in rice. Field Crops Res $1995 ; 40$ : 67-86.

14. PASSIOURA JB. Water in the soil-plant-atmosphere continuum. Encycl Plant Physiol, New Series $1982 ; 12$ B : 5-33.

15. RICHARDS RA. Defining selection criteria to improve yield under drought Plant Growth Regul 1996 ; 20 : 157-66.

16. GILLIER P, SILVESTRE P. L'arachide. Paris, France : Maisonneuve et Larose, 1969.

17. BUNTING AH. A classification of cultivated groundnuts. Empire Journal of Experimental Agriculture $1955 ; 23$ : 158-70.

18. ISLEIB TG, WYNNE JC, NIGAM SN. GROUNDNUT BREEDING. In : Smartt ], ed. The Groundnut Crop: A Scientific Basis for Improvement. Londres, GB Chapman \& Hall, 1994 : 553-616.

19. KHALFAOUI JLB. Genetic adaptation to drought of cultivated species and consequences on plant breeding. Bull Soc Bot Fr 1990 ; 137 : 125-37.

20. CLAVEL D, ANNEROSE DJ. Breeding groundnut for drought adaptation in Senegal. International Arachis Newsletter 1997 ; 17 : 33-5.

21. DOS SANTOS V, GIMENES M, VALLS J, LOPEZ C. Genetic variation within and among species of five sections of the genus Arachis L. (Leguminosae) using RAPDs. Gen Res Crop Evol 2003 ; $50: 841-8$.

22. BERTIOLI DJ, LEAL-BERTIOLI SCM, LION MB, et al. A large scale analysis of resistance gene homologues in Arachis. Mol Gen Genomics 2003; 270 : 34-45.

23. NOBILE PAULA M, GIMENES MARCOS A, VALLS JOSE FRANCISCO M, LOPES CATALINA R. Genetic variation within and among species of genus Arachis, section Rhizomatosae. Genet Resour Crop Evol 2004 ; 51 : 299-307.
24. KRAMER P. Drought, stress, and the origin of adaptations. In : Turner NC, Kramer PJ, eds. Adaptations of Plants to Water and High Temperature Stress. New York : Academic Press, 1980 : 7-20.

25. LEVITT J. Responses of plants to environmental stresses. In : Water, radiation, salt and others stresses, Vol I. New York, USA. 1980 : 395-434.

26. TURNER NC. Drought resistance: A comparison of two frameworks. In : Saxena NP, et al., eds. Management of Agricultural Drought: Agronomic and Genetic Options. New Delhi, Inde : Oxford IBH, 2000 : 5-12.

27. BAKER F. Conclusions. In: Baker FWG, ed. Drought Resistance in Cereals. Paris, France : ICSU Press, 1989 : 213-20.

28. LUDLOW MM, MUCHOW R. A critical evaluation of traits for improving crop yields in water limited environments. Adv Agron 1990 ; 43 : 107-53.

29. PASSIOURA JB. Grain yield, harvest index and water use of wheat. / Aust Agric Sci $1977 ; 43: 117-20$.

30. FISHER R. Optimizing rhe use and the water and nitrogen through breeding of crops. Plant Soil $1981 ; 58: 249-78$.

31. TURNER NC. Further progress in crop water relations. Adv Agron 1997 ; 58 : 293-338.

32. MADHUSUDHAN KV, GIRIDARAKUMAR S, RANGANAYAKULU GS, REDDY PC, SUDHAKAR C. Effect of water stress on some physiological responses in two groundnut (Arachis hypogaea L.) cultivars with contrasting drought tolerance. J Plant Biology $2002 ; 29$ : 199-202.

33. SUBBARAO GV, IOHANSEN C, SLINKARD AE, NAGESWARA RAO RC, SAXENA NP, CHAUHAN YS. Strategies for improving drought resistance in grain legume. Crit Rev Plant Sci 1995 ; 14 : 469-523.

34. ANNEROSE DJM. Critères physiologiques pour I'amélioration de I'adaptation à la sécheresse de l'arachide. Oléagineux $1988 ; 43$ : 217-21.

35. NDUNGURU B], NTARE BR, WILLIAMS TH, GREENBERG DC. Assessment of groundnut cultivars for end-of-season drought tolerance in Sahelian environment. J Agric Res (Camb) 1995 ; 125 : 79-85.

36. NAGESWARA RAO RC, SARDAR S, SIKAVUMAR MKV, SRIVASTAVA KL, WILLIAMS JH. Effect of water deficit at different growth phases of peanut. I. Yield responses. Agron / 1985 ; 77 : 782-6.

37. NAUTIYAL PC, RAVINDRA V, JOSHI JC. Gas exchange and leaf water relations in two peanut cultivars of different drought tolerance. Biol Plant 1995 ; $37: 371-4$.

38. KHALFAOUI JLB. Determination of potential lengths of the crop growing period in semi-arid regions of Senegal. Agric For Meteorol 1991 ; 55 : 351-63.

39. CRAUFURD PQ, WHEELER TR, ELLIS RH, SUMMERFIELD R]. Escape and tolerance to high temperature at flowering in groundnut. J Agric Res (Camb) $2000 ; 135: 371-8$

40. KHALFAOUI JL. Conduite de I'amélioration génétique de I'adaptation à la sécheresse en fonction des mécanismes physiologiques. Oleagineux 1985 ; $40: 329-34$.

41. KETRING D. Root diversity among peanut genotypes. Crop Sci 1984 ; 24 : 229-32.

42. WRIGHT GC, HUBICK K, FARQUHAR GD. Physiological analysis of peanut cultivar response to timing duration of drought stress. Aust J Agric Res 1991 ; 42 : 453-70.

43. PASSIOURA JB. The yield of crops in relation to drought. In : Boote KJ, et al., eds. Physiology and Determination of Crop Yield. Madison, WI, USA : Crop Science Society of America, 1994 : 343-59.

44. KHALFAOUI JL, HALWARD M. Screening peanut cultivar in the field for root growth : a test by herbicide injection in the soil. Field Crops Res 1993 ; 32 : 173-9.

45. MIA M, YAMANCHI A, KONO Y. Root system structure of six food legume species: inter- and intraspecific variations. Jpn / Crop Sci 1996 ; 65 : 131-40. 
46. OGBONNAYACl, SARRB, BROU C, DIOUF O, DIOP NN, ROY MACAULEY H. Selection of cowpea genotypes in hydroponics, pots, and field for drought tolerance. Crop Sci $2003 ; 43$ : 1114-20.

47. BENNETT JM, BOOTE KJ, HAMMOND LC. Relationship among water potential components, relative water content, and stomatal resistance of fieldgrown peanut leaves. Peanut Sci $1984 ; 11$ : 31-5.

48. LEPORT L, TURNER NC, FRENCH R, et al. Physiological responses of chickpea genotypes to terminal drought in a Mediterranean-type environment. Eur J Agron $1999 ; 11$ : 279-91.

49. CLAVEL D, SARR B, MARONE E, ORTIZ R. Potential agronomic and physiological traits of Spanish groundnut varieties (Arachis hypogaea L.) as selection criteria under end-of-cycle drought conditions. Agronomie $2004 ; 24$ : 1-8.

50. DAVIES W], TARDIEU F, TREJO C. How do chemical signals work in plant that grow in driyng soil? Plant Physiol $1994 ; 104: 309-14$.

51. QUARRIE S, PEKIC S, LAZIC-PEKIC S, IVANOSEVIC V, VASIC G. ABA and drought tolerance in maize: Future prospects. In : Maize Research Institute, Videnovic Z, eds. Maize Breeding Production and Utilization : 50 years of Maize Research Institute. Belgrade, Yougoslavie : Zemin Polje, 1995 : 121 37.

52. GALLARDO M, TURNER NC, LUDVIC C. Water relations, gas exchange and abscissic acid content in Lupinus cosentinii leaves in response to driyng different proportions of the root system. J Exp Bot 1994 ; 45 : 909-18.

53. CLAVEL D, DRAME NK, ROY-MACAULEY H, BRACONNIER S, LAFFRAY D. Analysis of early variations in responses to drought of groundnut (Arachis hypogaea L.) cultivars for using as breeding traits. Environ Exp Bot 2005 ; (sous presse)

54. TURNER NC, JONES MM. Turgor maintenance by osmotic adjustment : A review and evaluation. In : Turner NC, Kramer PJ, eds. Adaptation of Plants to Water and High temperatures Stress. New York, USA : Wiley, $1980:$ 87-103.

55. MORGAN J, CONDON A. Water use, grain yield and osmoregulation in wheat. Aust J Plant Physiol $1986 ; 13: 523-32$.

56. CLAVEL D, ANNEROSE DJM. GENETIC IMPROVEMENT OF GROUNDNUT ADAPTATION TO DROUGHT. In : Risopoulos S, ed. Research Projects, Summaries of the Final Reports STD2, UE-DG12. Wageningen, Pays-Bas: CTA, $1995: 33-5$.

57. BLUM A, EBERCOM A. Cell membrane stability as a mesure of drought and heat tolerance in wheat. Crop Sci $1981 ; 21: 43-7$.

58. GAFF D. Protoplasmic tolerance in extreme water stress. In : Turner NC, Kramer PJ, eds. Adaptation of Plants to Water and High Temperature. New York, USA. 1980 : 207-30.

59. BAJJI M, KINET JM, STANLEY L. The use of the electrolyte leakage method for assessing cell membrane stability as a water stress tolerance in durum wheat. Plant Growth Regul $2002 ; 36: 61-70$.

60. COSTA FRANÇA MG, PHAM THI AT, PIMENTEL C, PEREYRA ROSSIELLO RO, ZUILY-FODIL Y, LAFFRAY D. Differences in growth and water relation among Phaseolus vulgaris cultivars in response to induces drought stress. Environ Exp Bot $2000 ; 43: 227-337$.

61. DHANDA S, SETHI G. Tolerance to drought stress among selected Indian wheat cultivars. J Agric Res (Camb) $2002 ; 139$ : 319-26

62. SRINIVASAN A, TAKEDU H, SENBOKU T. Heat tolerance in food legumes as evaluated by cell membrane thermostability aqand chlorophyll fluorescence technique. Euphytica $1996 ; 88$ : 35-45.

63. MARONE A, ANNEROSE DIM. Effect of late drought on water relation and production of field grown peanut. In : INRA, ed. Proceedings Interdrought 95. 31 août - 2 septembre 1995, Montpellier. 1995 ; (section VII).

64. ANNEROSE DJM. Recherches sur les mécanismes d'adaptation à la sécheresse. Application au cas de l'arachide cultivée au Sénégal. Thèse soutenue à I'Université de Paris 7, 1990. 281 p.
65. VASQUEZ-TELLO A, ZUILY-FODIL Y, PHAM THI AT, VIEIRA DA SILVA JB. Electrolyte and Pi leakages and soluble sugar content as physiological tests for screening resistance to water stress in Phaseolus and Vigna species. J Exp Bot $1990 ; 41: 827-32$

66. LAURIANO JA, LIDON FC, CAMPOS PS, CA C, DO CEU MATOS M. Drought effect on cell membrane lipids and photosynthetic activity in different peanut cultivars. Photosynthetica $2000 ; 32: 7-12$.

67. SAHSAH Y, CAMPOS P, GAREIL M, ZUILY-FODIL Y, PHAM THI AT. Enzymatic degradation of polar lipids in Vigna unguiculata leaves and influence of drought stress. Physiol Plant $1998 ; 104$ : 557-86.

68. MATOS AR, D'ARCY-LAMETA A, FRANÇA M, et al. A novel patatin-like gene stimulated by drought stress encodes a galactolipid hydrolase. FEBS lett $2001 ; 491$ : 188-92.

69. FERRARI-ILIOU R, EL MAAROUF H, PHAM THIAT, D'ARCY LAMETAA, GAREIL M, ZUILY-FODIL Y. Cloning and sequencing of a CDNA encoding a Cowpea ascorbate peroxidase and gene expression under drought. $C R$ Soc Biol $1996 ; 190: 666$.

70. ROY-MACAULEY H, ZUILY-FODIL Y, KIDRIC M, PHAM THI AT, VIEIRA DA SILVA JB. Effect of water stress on proteolytic activities of cell compartments of Phaseolus and Vigna leaves from sensitive and resistant plants. Physiol Plant $1992 ; 85: 90-6$.

71. CRUZ DE CARVALHO MH, D'ARCY-LAMETA A, ROY-MACAULEY H, et al. Aspartic proteinase in leaves of common bean (Phaseolus vulgaris $\mathrm{L}$.) and cowpea (Vigna unguiculata L. Walp.): enzymatic activity, gene expression and relation to drought susceptibility. FEBS Lett $2001 ; 492$ : 342-6.

72. EL MAAROUF H, ZUILY-FODILY, GAREIL M, D'ARCY-LAMETA A, PHAM THI AT. Enzymatic activity and gene expression under water stress of phospholipase $\mathrm{D}$ in two cultivars of Vigna unguiculata L.Walp differing in their drought tolerance. Plant Mol Biol 1999 ; 39 : 1257-65.

73. COLOM M, VAZZANA C. Photosynthesis and PSII functionnality of droughtresistant and drought- sensitive weeping lovegrass. Environ Exp Bot 2003; 49 : 135-44.

74. RIZZA F, PAGANI D, STANCA A, CATTTIVELLI L. Use of chlorophyll fluorescence to evaluate cold acclimatation and freezing tolerance of winter spring oat. Plant Breed $2001 ; 120$ : 389-96.

75. GLYNN CP, COLIN N. Identification of drought tolerant woody perennial using chlorophyll fluorescence. J Arboriculture $2002 ; 28: 215-23$.

76. SINCLAIR TR, LUDLOW MM. Who taught plants thermodynamics? The unfulfilled plant water potential. Aust J Plant Physiol $1985 ; 12$ : 213-7.

77. FLOWER D, LUDLOWMM. Variations among accessions of pigeonpea (Cajanus cajan) in osmotic adjustment and dehydratation tolerance of leaves. Field Crops Res 1987 ; 17 : 229-43.

78. LIILEY J, LUDLOW MM, MCCOUCH S, O'TOOLE J. Locating QTL for osmotic adjustment and dehydration tolerance in rice. J Exp Bot 1996 ; 47 : 1427-36.

79. BIDINGER FR, WITCOMBE J. Evaluation of specific drought avoidance trait as selection criteria for improvement of drought resistance. In : Baker FWG, ed. Drought Resistance in Cereals. Paris, France : ICSU Press, 1989 : 213-20.

80. NAGESWARA RAOR, WILLIAMS JH, WADIA KDR, HUBICK K, FARQUHAR GD. Crop growth, water use effuiciency and carbon isotope discrimination in groundnut (Arachis hypogaea L.) genotypes under end-ofseason water deficit. Ann Appl Biol 1993 ; 122 : 357-67.

81. GREENBERG DC, WILLIAMS JH, NDUNGURU B]. Differences in yield determining processes of groundnut (Arachis hypogaea L.) genotypes in varied drought environments. Ann Appl Biol $1992 ; 120$ : 557-66.

82. WILLIAMS JH, SAXENA NP. The use of non-destructive measurement and physiological models of yield determination to investigate factors of determining differences in seed yield between genotypes of 'desi' chickpeas (Cicer arietinum). Ann Appl Biol 1991 ; 119 : 105-12. 
83. GAUTREAU J. Levels of intervariety leaf potentials and adaptation of groundnut to drought in Senegal. Oléagineux 1977 ; 32 : 323-32.

84. FARQUHAR G, RICHARD R. Isotopic composition in plant carbon correlates with water-use efficiency in wheat genotypes. Aust J Plant Physiol 1984 ; 11 : 539-52.

85. HALL AJ, RICHARD G, CONDON A, WRIGHT GC, FARQUHAR G. Carbon isotope discrimination and plant breeding. Plant Breed Rev 1993; 12 : 81-113.

86. WITHE JW. Implications of carbon isotope discrimination studies for breeding common bean under water deficits. In : Ehleringer JR, Farquhar GD, Hall $A E$, eds. Stable Isotope and Plant Carbon-Water relations. San Diego, USA : Academic Press, 1993 : 387-98.

87. MATUS A, SLINKARD A, VAN KESSEL C. Carbon isotope discrimination and indirect selection for seed yield in lentil. Crop Sci 1995 ; 35 : 679-84.

88. WRIGHT GC, RAO RCN, BASU MS. Selection for water-use efficiency in food legume-Extension phase report. ACIAR Food Legume Newsletter 1998; 27 : 4-6.

89. BRAY E. Plant responses to water deficit. Trends Plant Sci 1997 ; 2 : 48-54.

90. INGRAM J, BARTELS D. The molecular basis of dehydration in plants. Annu Rev Plant Physiol $1996 ; 47: 377-403$

91. YAMAGUCHI-SHINOZAKI K, et al. Development of drought-resistant and water stress-tolerant crops through biotechnology. In : JIRCAS, ed. Proceedings of the 8th JIRCAS International Symposium, Water for Sustainable Agriculture in Developing Regions: More Crop for Every Scarce Drop. Tsukuba, 27-28 November 2001. 2002 : 23-34.

92. KNIGHT H. Calcium signaling during abiotic stresses in plants. Crit Rev Cytol $2000 ; 195: 269-325$

93. THOMASHOW M. Plant cold acclimatation: Freezing tolerance genes and regulatory mechanisms. Plant Mol Biol 1999 ; 50 : 605-17.

94. XIONG L, ZHU J. Molecular and genetic aspects of plant responses to osmotic stress. Plant Cell Environ $2002 ; 25$ : 131-9.

95. JACOB T, RITCHIE S, ASSMAN S, GILROY S. Abscissic acid signal transduction in guard cells is mediated by phospholipase D activity. Proc Natl Acad SCi USA $1999 ; 9: 12192-7$.

96. SHINOZAKI K, YAMAGUCHI-SHINOZAKI K. Molecular response to dehydration and low temperature: Differences and cross-talk between two stress signaling pathways. Curr Opin Plant Biol $2000 ; 3$ : 217-23.

97. WANG W, VINOCUR B, ALTMAN A. Plant responses to drought, salinity and extreme temperatures: Towards genetic engineering for stress tolerance. Planta $2003 ; 218: 1-14$.

98. LIU X, KASUGA M, SAKUMA Y, et al. Two transcription factors DREB1 and DREB2, with EREB/AP2 DNA binding domain separate two cellular signal transduction pathways in drought- and low- temperature-responsive gene expression, respectively. Arabidopsis Plant Cell 1998; 10 : 1391-406.

99. FRANK W, MUNNIK T, KERKMANN K, SALIMINI F, BARTELS D. Water deficit triggers phospholipase $D$ activity in the resurrection plant Craterostigma plantagineum. Plant Cell $2000 ; 12: 111-23$.

100. EL MAAROUF H, ZUILY-FODIL Y, GAREIL M, D'ARCY-LAMETA A, PHAM THI AT. Cloning and expression under drought of CDNAs coding for two PI-PLCS in cowpeas leaves. Plant Physio Biochem 2001 ; 39 : 167-72.

101. YAMAMOTO Y, CONKLING M, SUSSEX I. An Arabidopsis CDNA related to animal phospholipide-specific phospholipase genes. Plant Physiol 1995 ; $107: 1029-30$.

102. PHAM THI AT, VIEIRA DA, SILVA JB, MAZLIAK P. The role of membrane lipids in plant resistance to water stress. Bull So Bot Fr $1990 ; 137$ : 199-214.

103. BARRETT A. The classes of proteolytic enzymes. In : Dalling M, ed. Plant Proteolytic Enzymes. Boca Raton, USA : CRC Press, 1986.
104. ESTELLE M. Proteases and cellular regulation in plants. Curr Opin Plant Biol $2001 ; 4$ : 254-60.

105. BROWN W, RYAN C. Isolation and characterization of a wound-induced trypsin inhibitor for alfafa leaves. Biochemistry $1984 ; 23$ : 3418-22.

106. LI L, LI CX, LEE G, HOWE G. Distinct roles for jasmonate synthesis and action of systemic wound responses of tomato. Proc Natl Acad Sci USA 2002 ; 99 : 6416-21.

107. RYAN C, MOURA D. Systeminic wound signaling in plants: a new perception. Proc Natl Acad Sci USA 2002 : 6519-20.

108. MARTINS L. Activation of multiple interleukin -1- $\beta$ converting enzyme homologues in cytosol and nuclei of HL-60 cells during etoposide-induced apoptosis. J Biol Chem 1997 ; 272 : 7421-30.

109. TIAN R, ZHANG G, YAN C, DAI Y. Involvment of poly(ADP-ribose) polymerase and activation of caspase-like protease in heat shock-induced apoptosis in tobacco suspension cells. FEBS Lett $2000 ; 474: 11-5$.

110. KORTHOUT H, BERICKI G, BRUIN W, VAN DUJIN B, WANG M. The presence and sub-cellular localization of caspase 3-like proteinases in plant cells. FEBS Lett $2000 ; 475: 139-44$

111. MARTILLA S, JONES N, MIKKONEN A. Differential lolalization in two acid proteinases in germinating barley (Hordeum vulgare) seed. Plysiol Plant $1995 ; 81: 798-801$.

112. WATNABE H, ABE K, EMORI Y, HOSOOYAMA H, ARAI S. Molecular cloning and induced gibberellin expression of multiple cysteine proteinases of rice seeds (Orizains). J Biol Chem 1991 : 16897-902.

113. KUMAR G, KNOWLES N. Age of potato seed-tuber inflorescences protein synthesis during sprouting. Physiol Plant $1993 ; 89: 89-99$.

114. GAN S, AMASINO R. Making sense in senescence. molecular genetic regulation and manipulation of leaf senescence. Plant Physiol 1997 ; 113 : 313-9.

115. FORTHOEFEL N, CUSHMAN M, OSTREM J, CUSHMAN J. Induction of a cysteine protease cDNA from Mesembryanthenum crystallinum leaves by environmental stress and plant growth regulators. Plant Sci $1998 ; 136$ : 195-206.

116. KOIZUMI M, YAMAGUCHI-SHINOZAKI K, TSUJI H, SHINOZAKI K. Structure and expression of two genes that encode distinct drought-inducible cysteine proteinases in Arabidopsis thaliana. Gene 1993 ; 129 : 175-82.

117. WILLIAMS JH, BULMAN M, HUTLTLY A, PHILLIPS A, NIEILL S. Characterization of cDNA from Arabidopsis thaliana encoding a potential yhiol protease whole expression is induced independently by wilting and abscissic acid. Plant Mol Biol 1994 ; 25 : 259-70.

118. DIOP NN, KIDRIC M, REPELLIN A, GAREIL M, D'ARCY LAMETA A, PHAM THI AT, et al. A multicystatin easy induced by drought stress in Cowpea (Vigna unguiculana L. Walp) leaves. FEBS Lett (sous presse).

119. PILLAI M, YANAGIHARA S, AKIYAMA T. Molecular cloning and characterization of salt responsive genes in rice (Oryza sativa). J Plant Physiol 2001 ; 158 : 1189-94.

120. GADDOUR K, VICENTE-CARBOJOSA J, LARA P, ISABEL-LAMONEDA I, DIAZ I, CARBONERO P. A constititive cystatin-encoding gene from barley (Icy) reponds differentially to abiotic stimluli. Plant Mol Biol 2001; 45 : 599-608.

121. THOQUET $P$, GHERARDI M, JOUYRNET $P$, et al. The molecular genetic linkage map of the model legume Medicago truncatula: an essential tool for comparative legume genomics and the isolation of agronomically important genes. BMC Plant Biol $2002 ; 2: 1$.

122. ORTIZ R, EKANAYAKE I, MAHALAKSHMI V, et al. Development of droughtresistant and water-stress tolerant crops through traditional breeding. In : IIRCAS, ed. Proceedings of the 8th JIRCAS International Symposium. Water for Sustainable Agriculture in Developing Regions : More Crop for Every Scarce Drop. Tsukuba, 27-28 November 2001. 2002 : 11-21. 
123. SUBRAMANIAN V, GURTU S, NAGESWARA RAO, NIGAM SN. Identification of DNA polymorphism in cultivated groundnut using random amplified polymorphic DNA (RAPD) assay. Genome 2001 ; 43 : 656-60.

124. GALLAIS A. La sélection assistée par marqueurs. In : AUPELF-UREF, ed. Quel avenir pour l'amélioration des plantes?. Paris, France : John Libbey Eurotext, 1995 : 387-97.

125. STUBER CW, POLACCO M, LYN SENIOR M. Synergy of empirical breeding, marker assisted selection and genomics to increase crop yield potential. Crop Sci $1999 ; 39: 1571-83$.

126. STALKER HT. Peanut (Arachis hypogaea L.). Field Crops Res 1997 ; 53 : 205 17.

127. HERSELMAN L. Genetic variation among Southern African cultivated peanut (Arachis hypogaea L.) genotypes as revealed by AFLP analysis. Euphytica $2003 ; 133: 319-27$.

128. FERGUSON ME, BUROW MD, SCHULZE SR, et al. Microsatellite identification and characterization in peanut (A. hypogaea L.). Theor and Appl Gen $2004 ; 108: 1064-70$.

129. BHAGWAT AS, KRISHNA TG, JAWALI N, MITRA RK. Cloning and characterization of ribosomal RNA gene repeat unit from groundnut. Plant Cell Rep $2001 ; 20: 193-7$.

130. UPADHYAYA HD, ORTIZ R, BRAMEL P, SUBE S. Development of a groundnut core collection using taxonomical, geographical and morphological descriptors. Genet Resour Crop Evol 2003 ; 50 : 139-48.

131. HE G, PRAKASH CS. Identification of polymorpic DNA markers in cultivated peanut (Arachis hypogaea L.). Euphytica 1997 ; 97 : 134-49.

132. SINGH A, SMARTT J, SIMPSON CE, RAINA SN. Genetic variation vis-à-vis molecular polymorphism in groundnut (Arachis hypogaea L.). Gen Res Crop Eval $1998 ; 45: 119-26$.

133. HOPKINS MS, CASA AM, WANG T, et al. Discovery and characterization of polymorphic Simple Sequence Repeats (SSRs) in Peanut. Crop Sci 1999 ; 39 : 1243-7.

134. HE G. Microsatellites as DNA markers in cultivated peanut (Arachis hypogaed L.). BMC Plant Biol $2003: 3$.

135. KRAPOVICKAS A. The origin, variability and spread of the groundnut (Arachis hypogaea). In : Ucko RJ, W C, Dimbledy, eds. The Domestication and Exploitation of Plant and Animals. Londres, GB : Duckworth, 1969 : 427-40.
136. GREGORY WC, GREGORY MP. Groundnuts. In : Simmonds NW, ed. Evolution of Crop Plants. Londres : Longman, 1976 : 151-4.

137. UPADHYAYA HD. Phenotypic diversity in groundnut (Arachis hypogaea L.) core collection assessed by morphological and agronomical evaluations. Genet Resour Crop Evol 2003 ; 50 : 539-50.

138. SWAMY BPM, UPADHYAYA HD, GOUDAR PVK, KULLAISWAMY BY, SUBE $S$. Phenotypic variation for agronomic characteristics in a groundnut core collection for Asia. Field Crops Res 2003 ; 84 : 359-71.

139. KLUEVA NY, ZHANG J, NGUYEN HT. Molecular strategies for managing environmental stress. In : Copra VL, Singh RB, Varma PJ, eds. Crop Productivity and Sustainability: Shaping the Future, Proceeding of 2nd International Crop Science Congress. New Delhi, Inde : Oxford IBH, 1998 : 501-24.

140. CLAVEL D. Biotechnologies et arachide. OCL $2002 ; 9$ : 206-11.

141. RIBAUT JM, HOISINGTON DA, DEUTSCH JA， JIANG C, GONZALES DE, LEON D. Identification of quantitative trait loci under drought conditions in tropical maize. I Flowering parameter and the anthesis-silking interval. Theor Appl Genet 1996 ; 92 : 905-14.

142. FROVA C, KRAJEWSKI P, DI FONZO N, VILLA M, SARI-GORLA M. Genetic analysis of drought tolerance in maize by molecular markers. I Yield component. Theor Appl Genet 1999 ; 99 : 280-8.

143. MACKILL DJ, NGUYEN HT, JINGXIANG Z. Use of molecular markers in plant improvement programs for rainfed rice. Field Crops Res $1999 ; 64$ : 177-85.

144. JAIN KJ, BASHA SM, HOLBROOK CC. Identification of drought responsive transcripts in peanut (Arachis hypogaea L.). EJB. Electron J Biotechnol 2001 : 9.

145. GUO B, YU J, HOLBROOK C, LEE R, LYNCH R. Application of differential display RT-PCR and EST/microarray technologies to the analysis of gene expression in response to drought stress and elimination of aflatoxin contamination in corn and peanut. J Toxicol Toxin Rev $2004 ; 22$ : 287-312.

146. CLAVEL D, DRAME NK, DIOP NN, ZUILY-FODIL Y. Outils moléculaires pour I'étude de I'adaptation à la sécheresse chez I'arachide. In: El Hadrami I, Daayf $\mathrm{F}$, eds. Biotechnologies végétales : de la structure des génomes à l'amélioration des plantes, VII I mes journées scientifiques du réseau "Biotechnologies, Amélioration des Plantes et Sécurité Alimentaire". Marrakech, 7-9 octobre 2002. $2003: 290-307$ 